\title{
IDEOLOGI T-SHIRT BEBASKAN JRX SEBAGAI SEBUAH KOMODITI DAN SIMBOL PERLAWANAN TERHADAP KEKUASAAN
}

Ida Ayu Dwita Krisna Ari $^{1}$, Made ika Kusuma Dewi ${ }^{2}$

Institut Seni Indonesia Denpasar, UHN I Gusti Bagus Sugriwa Denpasar

Abstract

Clothing has become an important part of the lifestyle and has become a fashion trend in Balinese society. Clothing is very closely related to the human self, through clothing can reveal many things about the identity of the wearer from the appearance reflected how the social status and personality of the wearer. Currently, the t-shirt is a popular clothing used by people from all walks of life because it is easy to clean and the model remains eternal from time to time. T-shirts have several conveniences, apart from being cheap, comfortable to wear, easy to clean, mobile, functional, and can be used as souvenirs, and so on, this makes business people and politicians realize that $t$-shirts can be used as a gift. an effective and efficient promotional media, apart from being a means of advertising t-shirts, it is also used as a medium to spread political understanding. Of the several functions possessed by the $t$-shirt, it is related to the function of the $t$-shirt as a medium for delivering messages and aspirations. Currently, several types of $t$-shirts have emerged that carry the aspirations of several groups of people who empathize with the case that befell the drummer for the Superman Is Dead band, I Gede Ari Astina, or who is familiarly called Jerink, later shortened to JRX. Regarding this case, many JRX sympathizers thought that he did not deserve to be punished, without holding mediation to bridge the problem between JRX and IDI Bali which he criticized, but the JRX case went straight to the legal process so that it was considered by some groups of society as an act. silence the aspirations of the small people who try to voice injustice in this country, therefore several individual formation practices have emerged that determine their common social orientation, this community movement group has the same ideology and so that they can act structurally so that it is in line with their ideology. stretcher, then in the process of marking the ideology, several t-shirt designs emerged with the theme "free JRX" with various variants, designs, colors that emerged from several groups that had the same ideology.

\footnotetext{
${ }^{1}$ krisnaaridwita@isi-dps.ac.id
}

2 kusumaika@uhnsugriwa.ac.id 


\section{PENDAHULUAN}

Pakaian menjadi bagian penting dari gaya hidup dan menjadi sebuah trend berpenampilan dalam masyarakat di Bali. Pakaian sangat erat kaitannya dengan diri manusia, melalui pakaian dapat mengungkap banyak hal tentang identitas pemakainya dari penampilan tercermin bagaimana status sosial dan kepribadian pemakainya. Saat ini t-shirt merupakan pakaian populer yang digunakan masyarakat dari kalangan manapun karena sifatnya yang mudah dibersihkan dan modelnya tetap kekal dari waktu ke waktu. Semenjak revolusi t-shirt terjadi secara total dan seiring berjalannya waktu saat ini t-shirt menjadi pakaian populer dikalangan masyarakat, mulai dari balita, anak - anak, dewasa, hingga orang tua, laki - laki maupun perempuan memakai t-shirt sebagai pakaian sehari-hari.

T-shirt merupakan pakaian yang menutupi sebagian lengan, seluruh dada, bahu dan perut tidak memiliki kancing dan kantong, umumnya $\mathrm{t}$ - shirt berkerah bundar atau kerah berbentuk huruf " $V$ " atau biasa juga disebut "V Neck",menggunakan bahan katun atau poliester bahkan gabungan keduanya. T-shirt semakin diterima sebagai pakaian luar dan menjadi lebih dari sekedar pakaian karena sekaligus merupakan media ekpresi, ideologis dan identitas. T-shirt mampu menjadi teks terbuka yang mengkomunikasikan pesan tertentu melalui bentuk, gambar, atau kata-kata mengenai pengalaman, perilaku dan status sosial. Tshirt memiliki beberapa kemudahan, selain karena harganya yang murah, nyaman dipakai, mudah dibersihkan, bersifat mobile, fungsional, serta dapat dijadikan souvenir, dan lain sebagainya, hal ini membuat para pelaku bisnis dan juga politikus menyadari bahwa t-shirt dapat dijadikan sebagai media promosi yang efektif dan efisien, selain sebagai sarana beriklan t-shirt juga dijadikan sebagai media untuk menyebarkan paham politik. Saat ini t-shirt bukan saja dilihat sebagai sebuah kebutuhan pokok, berfungsi untuk melindungi tubuh dari cuaca namun tshirt memiliki nilai fungsi yang jauh melebihi fungsi pokoknya yaitu sebagai sebuah produk industri yang mampu menyampaikan segala pesan, aspirasi, dan pandangan berpolitik. dalam Buku Fashion Sebagai Komunikasi, oleh Barnard Malcom (1996 : 83) bahkan dikatakan bahwa fashion dan pakaian secara simbolis dapat mengikat satu komunitas, hal ini menunjukkan bahwa kesepakatan sosial atas apa yang akan dikenakan merupakan ikatan sosial itu sendiri yang pada gilirannya akan memperkuat ikatan sosial lainnya.

Dari beberapa fungsi yang dimiliki oleh t-shirt, berkaitan dengan fungsi t-shirt sebagai media penyampaian sebuah pesan dan aspirasi saat ini muncul beberapa jenis tshirt yang mengusung aspirasi beberapa golongan masyarakat yang berempati terhadap kasus yang menimpa drummer band Superman Is Dead yang bernama I Gede Ari Astina atau yang akrab dipanggil Jerink kemudian disingkat menjadi JRX. Seperti yang kita ketahui JRX dilaporkan oleh Ikatan Dokter Indonesia (IDI) Bali karena status media sosialnya dianggap mencemarkan nama baik IDI Bali, JRX didakwa melakukan tindak pidana dan dijerat dengan pasal 28 ayat (2) Jo pasal 45A ayat (2) UU ITE, sebagai pemenuhan proses 
administrasi maka dilakukan penahanan oleh pihak kepolisian.

Terkait dengan kasus tersebut, banyak simpatisan JRX yang menganggap bahwa ia tidak pantas untuk di pidana, tanpa digelarnya mediasi untuk menjembatani permasalahan antara pihak JRX dan IDI Bali yg dikritiknya namun kasus JRX langsung masuk ke proses ranah hukum sehingga dianggap oleh beberapa golongan masyarakat merupakan sebuah tindakan membungkam aspirasi rakyat kecil yang berusaha menyuarakan ketidakadilan di negeri ini, oleh sebab itu muncullah beberapa praktik - praktik pembentukan individu yang menentukan kesamaan orientasi sosial mereka, kelompok gerakan masyarakat ini memiliki ideologi yang sama dan agar mereka dapat bertindak secara struktur sehingga selaras dengan ideologi yang mereka usung, maka dalam proses penandaan ideologi tersebut muncullah beberapa desain $\mathrm{t}$-shirt yang bertema "bebaskan JRX" dengan berbagai varian, desain, warna yang muncul dari beberapa kelompok yang memiliki kesamaan ideologi.

T-shirt ini dikenakan saat mereka sedang melakukan berbagai kegiatan yang menyuarakan aspirasi mereka terhadap pembebasan JRX baik melalui kegiatan unjuk rasa, bagi - bagi pangan, sembahyang bersama, atau kegiatan bersih - bersih pantai yang diunggah melalui akun media sosial masing - masing kelompok. Umumnya setiap kelompok memiliki desain t-shirtnya masing - masing, t-shirt ini dijual dengan harga yang variatif mulai dari seratus ribu rupiah hingga seratus lima puluh ribu rupiah, hasil penjualannya sebagian digunakan untuk mendanai aksi sosial mereka. Berbagai pengembangan akan t-shirt bebaskan JRX ini semakin banyak bermunculan dengan berbagai versi, t-shirt ini mulai merambah memasuki nilai komersil yang dibuat bukan murni untuk tujuan kegiatan sosial namun juga untuk meraup keuntungan dari antusias masyarakat yang tertarik menggunakan tshirt tersebut sebagai sebuah pencitraan diri sebagai bagian dari sebuah pergerakan sosial yang lambat laun mulai berkembang dari awalnya hanya digunakan saat melakukan aksi unjuk rasa namun sekarang digunakan dalam kegiatan - kegiatan sosial maupun kegiatan yang sifatnya non sosial.

\section{METODE PENELITIAN}

Metodelogi yang digunakan adalah metode kualitatif untuk memahami fenomena tentang apa yang dialami oleh subyek penelitian secara holistik dalam bentuk kata - kata dan bahasa (Moleong, 2010:6) dengan mengumpulkan, menyaring dan menganalisis data dari subjek kajian ini yaitu desain t-shirt yang bertema "bebaskan JRX". Penyeleksian desain t-shirt menggunakan tehnik purposive sampling (penyampelan purposif), dari sejumlah $\mathrm{t}$ shirt yang muncul terkait dengan kasus penahanan JRX, penulis memilih menggunakan dua tshirt yang pertama adalah t-shirt bertuliskan "bebaskan JRX" yang dibuat oleh komunitas frontier Bali dan yang kedua adalah t-shirt "bebaskan JRX' dari sudut solid peguyangan, keduanya dipilih karena memiliki pesan verbal bertuliskan "bebaskan JRX. Sebelum penelitian ini dilakukan, penulis observasi serta identifikasi awal terhadap beberapa desain t-shirt yang muncul selama fenomena kasus penahanan JRX. Data tentang t-shirt dikumpulkan dengan metode observasi dan dokumentasi. Observasi dilakukan pada pengamatan beberapa desain $t$-shirt, metode dokumentasi digunakan dengan membaca sejumlah tulisan yang berkaitan dengan $\mathrm{t}$-shirt pada buku maupun jurnal. 
Selanjutnya desain t-shirt di analisis dari segi teks visual dan teks verbalnya, kemudian pemahaman mengenai ideologi yang terkandung dalam desain t-shirt dipaparkan melalui pembacaan tanda teks visual dan verbal yang ada pada t-shirt bebaskan JRX.

Sejumlah buku yang mengulas mengenai t-shirt yang berjudul Budaya Populer Sebagai Komunikasi oleh Idi Subandi Ibrahim ( 2007 : 271) mengatakan bahwa dalam modernitas, fashion dianggap sebagai unsur pokok identitas seseorang, yang membantu untuk menentukan bagaimana mereka dipahami dan diterima dalam masyarakat. Fashion menawarkan pilihan pakaian, gaya dan citra. Melalui pakaian, gaya dan citra ini seseorang dapat menghasilkan identitas individual. Berdasarkan pandangan Ibrahim di atas, fashion menawarkan pilihan pakaian, gaya dan citra yang nantinya dapat menghasilkan identitas individual bagi pemakainya, manfaat buku ini dalam penelitian penulis adalah sebagai awal pijakan untuk memahami fashion, dalam hal ini adalah pakaian yang terkait dengan penelitian penulis, buku ini juga memaparkan bagaimana fungsi pakaian sebagai sebuah bentuk komunikasi serta mampu menyampaikan pesan artifaktual yang bersifat non verbal serta memaparkan fungsi lain pakaian sebagai ekspresi identitas pribadi bagi pemakainya yang nantinya akan dipakai sebagai acuan untuk membahas fungsi t-shirt Bebaskan JRX bagi pemakainya.

Buku Fashion Sebagai Komunikasi,

oleh Barnard Malcom (1996 : 83) mengatakan bahwa fashion dan pakaian secara simbolis mengikat satu komunitas. Hal ini menunjukkan bahwa kesepakatan sosial atas apa yang akan dikenakan merupakan ikatan sosial itu sendiri yang pada gilirannya akan memperkuat ikatan sosial lainnya. Merujuk pendapat Barnard di atas, maka relevansi buku ini bagi penelitian penulis sebagai pijakan untuk membahas fungsi t-shirt karena di dalamnya mengulas mengenai seluk beluk pakaian dan fashion sebagai sebuah alat komunikasi.

Buku Image and Idea (1990:61) yang ditulis oleh Edmund Burke Feldmen, manfaat buku ini dalam penelitian penulis adalah sebagai acuan untuk membahas fungsi dari sebuah karya seni dalam penelitian ini bertujuan untuk membahas fungsi t-shirt Bebaskan JRX.

Buku Teori Budaya Kontemporer ( 2018:107) yang ditulis oleh Yasraf Amir Piliang akan digunakan oleh penulis untuk membahas ideologi dan mitos - mitos kontemporer yg terkait dengan mitos modern yg lebih bersifat komersil, dalam hal ini keberadaan t-shirt bertema JRX adalah sebuah nilai komiditi yg dperjual belikan yg sifatnya komersil.

Buku Tentang Ideologi (2008:39) yang ditulis oleh Louis Althusser akan digunakan oleh penulis untuk membahas terkait ideologi sebagai sebuah representasi relasi individu imajiner pada kondisi nyata dari eksistensi.

Buku Prison Notebooks (2013:283) yang ditulis oleh Antonio Gramsci akan digunakan penulis untuk mengulas permasalahan mengenai hegemoni negara pada masyarakat sipil.

Buku Kreativitas dan Humanitas (2006:54) manfaat buku ini dalam penelitian penulis adalah karena memaparkan mengenai konsep kreativitas yang nantinya akan dipakai sebagai acuan untuk membahas konsep estetika dan konsep desain pada t-shirt Bebasakan JRX.

Buku Desain Komunikasi Visual Teori Dan Aplikasi (2010:18) karangan Rakhmat Supriyono, memaparkan unsur - unsur 
desain komunikasi visual manfaat buku ini dalam penelitian penulis adalah untuk menjawab permasalahan yang menyangkut konsep estetika pada desain t-shirt Bebaskan JRX.

Buku Semiotika Visual Konsep, Isu dan Problematika Ikonisitas karangan Kris Budiman (2011:38), membahas konsep konsep dasar semiotika manfaat buku ini dalam penelitian penulis adalah untuk menjawab permasalahan mengenai makna dalam penelitian penulis.

Buku Analisis Wacana karangan Alex Sobur (2009:9) menjelaskan mengenai definisi wacana, wacana ialah sebuah komunikasi pikiran dengan kata - kata, ekspresi, ide - ide, atau gagasan - gagasan, konversi atau percakapan, analisis wacana membahas bahasa dan tuturan harus di dalam rangkaian kesatuan situasi penggunaan yang utuh, dalam pengertian bahwa makna suatu bahasa berada pada rangkaian konteks dan situasi. Manfaat buku ini dalam penelitian adalah untuk membahas bagaimana realitas penggunaan tanda untuk mengungkapkan makna yang terkandung dalam t-shirt Bebaskan JRX dalam konteks ruang dan waktu dimana teks tersebut berlaku.

Jurnal yang berjudul T-shirt sebagai media perlawanan terhadap wacana reklamasi teluk benoa Bali yang ditulis oleh Ida Bagus Adi Wisudiatmika dalam jurnal studi kultural volume $V$ tahun 2020 menuliskan t-shirt sebagai media perlawanan terhadap dominasi kapitalis mengkaji mengenai penandaan t-shirt dari konsep hingga ideologi apa yg melatarbelakangi sistem tanda yg dihasilkan, perbedaan penelitan dalam jurnal tersebut dengan penelitian ini adalah penulis lebih menekankan pada aspek - aspek mitos modern yg lahir dari ideologi yg diusung melalui t-shirt bebaskan JRX, bagaimana sebuah ideologi yg diusung pd akhrnya menjadi sebuah komoditi untuk meraup keuntungan sekelompok orang yang menghadirkan ideologi tersebut sebagai sebuah gerakan perjuangan namun di satu sisi meraup keuntungan dari ideologi yang dibangun tersebut.

Dalam penelitian ini menggunakan analisis deskriptif kualitatif dengan menguraikan atau menjabarkan sifat atau karakteristik data yang sebenarnya serta melihat faktor - faktor yang melatarbelakangi sifat - sifat data yang diperoleh. Data yang dideskripsikan adalah data yang diperoleh dari hasil pengumpulan data dengan menggunakan observasi, wawancara, dokumentasi dan kepustakaan dalam bentuk tulisan. Pengolahan data yang dilakukan dalam penelitian ini adalah dengan melakukan pemilihan data berdasarkan pokok-pokok bahasan dalam rumusan masalah. Penafsiran data dilakukan dengan memakai hasil data yang diperoleh dan pada akhirnya melakukan penarikan kesimpulan.

Teknik penyajian hasil penelitian mengacu kepada pembahasan kedua rumusan masalah, yang pertama adalah pembahasan terkait dengan bentuk desain $\mathrm{t}$ shirt bebaskan JRX, yang kedua adalah pembahasan mengenai ideologi apa yang terkandung pada desain t-shirt bebaskan JRX bagi penggunanya yang mengacu kepada teori ideologi, teori hegemoni, dan teori semiotika.

\section{PEMBAHASAN}

Bentuk Desain t-shirt Bertema Bebaskan JRX

Desain t-shirt pertama dari akun media sosial frontier Bali yang muncul pertama kali pada tanggal 13 September 
2020 t-shirt ini dijual dengan harga seratus ribu rupiah persatuannya, dengan berbagai varian ukuran mulai dari $S, M, L, X L$ dan $X X L$, dikatakan bahwa seluruh penjualan t-shirt ini digunakan untuk kepentingan gerakan aksi bebaskan JRX, t-shirt ini memiliki satu varian warna saja yaitu warna hitam dengan desain dominan berwarna merah. Desain tshirt tersebut terdiri dari tiga unsur yaitu ilustrasi, teks dan warna. Gaya ilustrasi menggunakan gaya flat desain yaitu teknik yang menggunakan skema desain yang tidak menyertakan atribut tiga dimensi, jenis huruf menggunakan huruf sans serif (huruf tidak berkait atau ujung hurufnya tidak memiliki kait), dan menggunakan warna primer yang merupakan dasar dari warna lain yaitu biru merah dan kuning (Gambar 1).

Teks Visual menghadirkan ilustrasi seorang laki - laki yang diletakkan pada bagian center desain dengan mengambil porsi yang paling besar dari keseluruhan desain sehingga menyebabkan terjadinya focus of interest pada desain t-shirt ini, pada bagian mulutnya tertutup oleh teks verbal "No Freedom of Speech" tangannya digambarkan menggenggam serta terikat oleh tali kabel, pada bagian belakang kiri laki - laki tersebut terdapat ilustrasi berupa dua buah toa (alat pengeras suara) yang pada bagian atas toa tersebut terdapat ilustrasi seperti halilintar sebanyak tiga buah, pada bagian kanan laki - laki tersebut terdapat ilustrasi seperti kobaran api, dibelakang ilustrasi toa dan kobaran api tersebut terdapat ilustrasi kotak - kotak seperti jeruji penjara yang berwarna hitam serta ilustrasi ikon pulau Bali. Di bagian atas dari keseluruhan desain terdapat ilustrasi burung yang sedang terbang. Layout yang digunakan pada desain ini adalah menggunakan keseimbangan simetris yaitu rata tengah.
Teks verbal dihadirkan untuk mendukung teks visual, teks verbal pada desain t-shirt ini menggunakan jenis huruf sans serif bertuliskan "Bebaskan JRX SID" pada headline bagian atas desain, teks bebaskan menggunakan warna hitam dan teks JRX SID menggunakan warna putih, di bagian tengah desain terdapat teks "No freedom of speech" menggunakan warna merah pada teks "NO" dan menggunakan warna putih pada teks "Freedom of speech" pada bagian bawah desain terdapat teks "kami bersama JRX" menggunakan warna putih.

Tanda visual dan tanda verbal yang dihadirkan pada desain t-shirt menghadirkan makna denotasi. Secara denotasi desain tshirt ini menghadirkan seorang laki - laki yang mulutnya tertutup oleh teks "No Freedom of Speech" laki - laki ini digambarkan dengan tangan terikat seutas tali, berdasarkan teks verbal yang menyebutkan "Bebaskan JRX SID" dan "Kami Bersama JRX" maka dapat dipastikan laki laki yang digambarkan tersebut adalah JRX SID atau Jerink yang bernama asli I Gede Ari Astina drummer grup band Superman Is Dead yang terkenal disingkat dengan nama SID.

\section{Ideologi Dalam Desain T-Shirt Bertema Bebaskan JRX}

Ideologi pada desain t-shirt ini adalah penggambaran terpidananya JRX atas kasus pencemaran nama baik yang dituduhkan oleh IDI (Ikatan Dokter Indonesia) Bali terkait dengan status sosial medianya yang mengatakan bahwa IDI (Ikatan Dokter Indonesia) adalah kacung WHO, dalam desain t-shirt digambarkan JRX dalam keadaan terikat tangannya menggunakan tali sebagai simbol bahwa ia adalah seorang terpidana yang sudah 
tertangkap dan tunduk pada kekuasaan hukum di Indonesia, dalam kasus ini bisa kita lihat bagaimana hegemoni negara terhadap masyarakat sipil dalam kinerja aparat kepolisian yang mungkin hanya menjalankan tugasnya sebagai penegak hukum karena polisi hanya bertindak secara positivistik, polisi hanya melihat konstruksi perkara lalu ditempelkan kepada delik pengaduan selanjutnya dipasangkanlah tali plastik di tangan JRX sebagai simbol seseorang terpidana kasus hukum, namun kemudian jika dilihat dari kacamata yang berbeda hal ini bisa dimaknai sebagai matinya demokrasi dan kebebasan berpendapat di negeri ini serta tindakan tersebut bisa dimaknai sebagai tindakan yang merendahkan orang lain karena pengikatan tangan tersebut tidak disesuaikan dengan konteks tindakan peristiwa atau tindak kejahatan yang dilakukan oleh JRX, layaknya seorang pelaku kriminal kelas kakap yang tindak kriminalitasnya seperti menghilangkan nyawa orang lain padahal yang ia lakukan hanyalah menyuarakan aspirasinya sebagai rakyat kecil yang mengkritisi kebijakan pemerintah terkait rapid test dan penanganan wabah covid di Indonesia. llustrasi pengeras suara berupa toa dan kobaran api dalam desain t-shirt dapat dimaknai sebagai lantangnya suara JRX yang menyuarakan berbagai pemikirannya yang ditandai dengan ikon halilintar dapat dimaknai sebagai proses penyuaraan pendapat dengan keras dan lantang, namun pada bagian mulut yang tertutup oleh teks "NO Freedom of Speech" bermakna pembungkaman terhadap JRX dengan cara menjebloskannya ke penjara sehingga tidak ada lagi kebebasan berbicara di negeri ini.

Teks "kami bersama JRX" menunjukkan empati dan solidaritas masyarakat yang memiliki ideologi dan kesamaan orientasi sosial, mereka lahir atas kesamaan pandangan sosial dan memiliki rasa empati terhadap kasus JRX sehingga menyebabkan terbentuknya komunitas kelompok-kelompok masyarakat yang mengusung ideologi perjuangan untuk membebaskan JRX SID. Dalam t-shirt ini mencantumkan teks "Bebaskan JRX SID" yang berisi ilustrasi burung yang sedang terbang dapat bermakna mengenai kebebasan yang dikonotasikan dengan ilustrasi burung yang terbang dari sangkar, dalam hal ini kebebasan JRX dari jeruji penjara. 

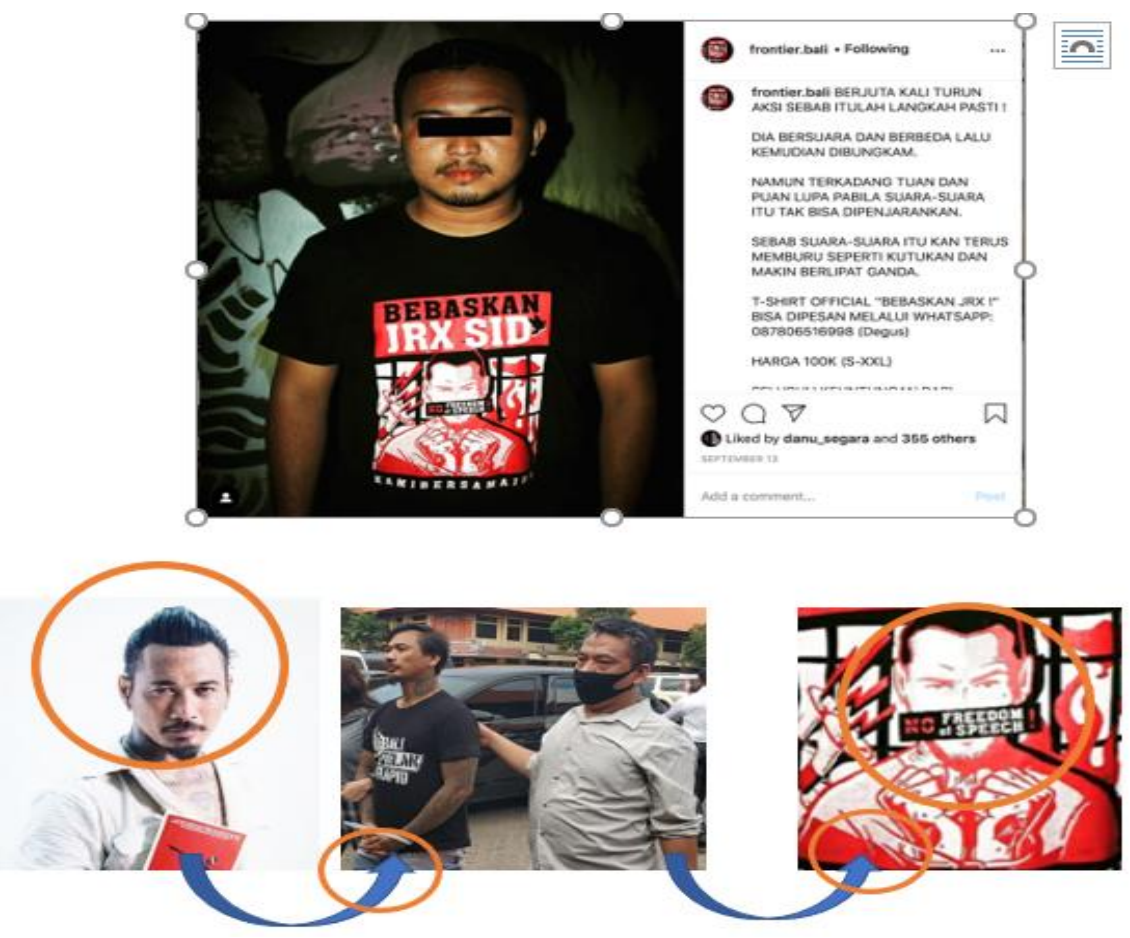

Gambar 1. Desain T-Shirt dari Akun Sosial Media Frontier Bali Diunggah tanggal 13 September 2020

Desain $t$-shirt kedua adalah desain $\mathrm{t}$ shirt yang lahir dari komunitas sudut solid Peguyangan, desain t-shirt ini pertama kali muncul dalam akun sosial media milik Danu_Segara pada tanggal 13 Oktober 2020, t-shirt ini terdiri dari beberapa varian ukuran dari size $S, M, L, X L$ dan $X X L$, harga t-shirt ini dibaderol seharga seratus ribu rupiah.
Desain $t$-shirt ini terdiri atas dua desain pada bagian depan dan desain pada bagian belakang t-shirt, pada bagian depan terdiri atas tiga unsur yaitu teks, ilustrasi dan warna sedangkan pada ilustrasi belakang terdiri atas unsur teks dan warna saja. Bagian depan t-shirt menggunakan penggayaan flat desain sedangkan pada bagian belakang desain hanya berupa huruf saja (Gambar 3).
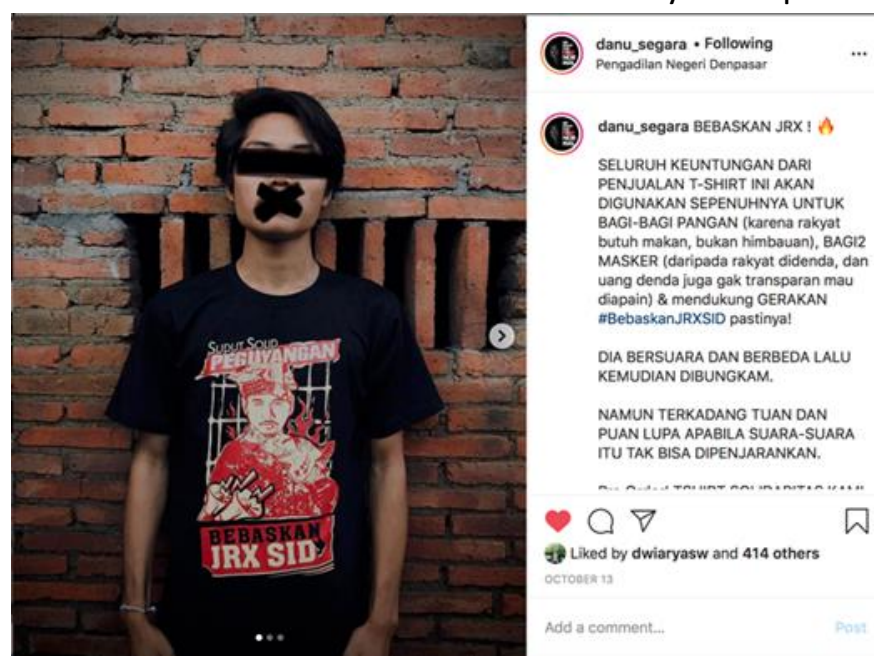

Gambar 2. Desain T-Shirt Dari Akun Sosial Media Danu_Segara yang Tampak dari Depan Diunggah tanggal 13 Oktober 2020 


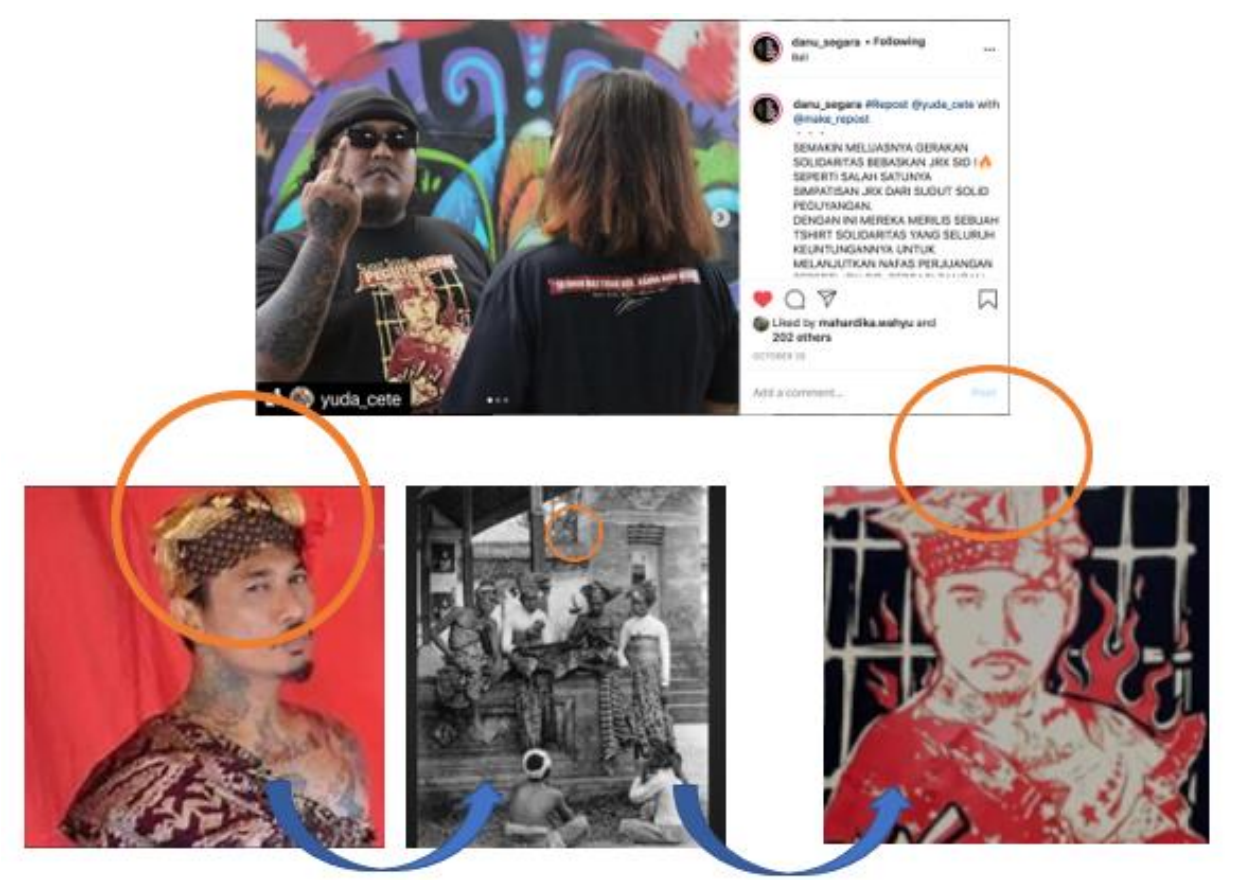

Gambar 3. Desain T-Shirt dari Akun Sosial Media Danu_Segara Yang Tampak dari Belakang Diunggah tanggal 13 Oktober 2020

Tanda Non Verbal atau teks visual menghadirkan ilustrasi seorang laki - laki yang menggunakan udeng, bertelanjang dada dengan badan penuh tattoo serta di dalam kain yang digunakan untuk menutupi bagian dada terselip sebuah senjata tradisional Bali berupa keris, di depan ilustrasi seorang pria tersebut terdapat ilustrasi dua buah toa pengeras suara dengan mengeluarkan icon halilintar sebanyak tiga buah, di bagian bawah ilustrasi tersebut terdapat ilustrasi burung yang sedang terbang, sedangkan pada bagian belakang ilustrasi laki - laki tersebut terdapat ilustrasi api dan kotak - kotak yang menyerupai jeruji penjara.

Tanda Verbal yang hadir dalam tampilan depan desain $t$-shirt adalah di bagian atas tertulis "Sudut Solid Peguyangan" sedangkan pada bagian bawah t-shirt tertulis "bebaskan JRX SID" desain belakang t-shirt tersebut hanya terdapat teks verbal saja yaitu pada bagian atas bertuliskan "leluhur Bali tidak buta, karma akan datang" pada bagian bawah terdapat tulisan "rutan polda Bali 27 Agustus 2020" dan di bawahnya terdapat tanda tangan dari pembuat desain tersebut.

Teks visual dan teks verbal pada desain t-shirt bebaskan JRX dari sudut solid Peguyangan pada bagian depan desain $t$ shirt adalah menggambarkan seorang laki laki yang badannya penuh tatto menggunakan ikat kepala berupa udeng dan di tengah kain yang menutupi badannya terselip sebuah senjata tradisional Bali berupa keris di depan ilustrasi laki - laki tersebut terdapat ilustrasi dua buah toa pengeras suara sedangkan di bagian belakangnya terdapat ilustrasi kobaran api dan jeruji penjara, diatas desain terdapat tulisan "sudut solid Peguyangan" dan di bagian bawah terdapat tulisan "Bebaskan JRX SID" ini menandakan t-shirt tersebut adalah dari komunitas sudut solid peguyangan dan "bebaskan JRX" merupakan 
sebuah harapan dari komunitas ini, di bagian belakang t-shirt juga terdapat tulisan "leluhur Bali tidak buta, karma akan datang" memiliki arti bahwa leluhur Bali tidak buta maka karma akan datang, di bawah teks tersebut bertuliskan "rutan Polda Bali 27 Agustus 2020" rutan polda Bali mengacu pada nama tempat yaitu Rumah Tahanan Polda Bali dan 27 Agustrus 2020 merupakan sebuah penandaan tanggal di bulan Agustus tahun 2020 tanggal 27.

Ideologi yang dapat dibawa oleh desain t-shirt di atas adalah bagaimana sosok JRX yang penuh tattoo menggunakan udeng sebagai simbol laki - laki Bali dan dalam kainnya yg dikenakannya untuk menutupi tubuh terselip sebuah keris dimana keris ini identik dengan makna sebuah perjuangan, karena pada jaman dahulu seorang ksatria di Bali selalu membawa keris yang diselipkan di dadanya, dapat dimaknai dari ilustrasi di atas bahwa itu adalah sebuah bentuk perjuangan JRX dari rakyat biasa yang berjuang melawan ketidak adilan terkait penanganan wabah covid yang ada di Indonesia, semangat perjuangan JRX tersebut dengan lantang dan berkobar yang ditandai dengan ilustrasi pengeras suara toa dan kobaran api, namun ada jeruji besi dibaliknya yang menandakan bahwa perjuangan JRX sudah terbelenggu dalam jeruji besi. Teks yang bertuliskan "sudut solid Peguyangan" menandakan bahwa pengguna t-shirt tersebut lahir dari komunitas sudut solid Peguyangan dimana sudut dapat diartikan tempat terpojok atau orang - orang yang tersudutkan berakhir menjadi sebuah solidaritas atau sudut solid yang lahir dari daerah Peguyangan, teks "bebaskan JRX SID" yang berisikan ilustrasi burung yang sedang terbang mengharapkan kebebasan JRX dari dalam jeruji besi. Pada bagian belakang baju yang bertuliskan "leluhur Bali tidak buta, karma akan datang" bermakna bahwa memenjarakan JRX merupakan sebuah proses hukum yang dinilai tidak tepat karena kasus yang dilakukan oleh JRX sebenarnya bisa dimediasi terlebih dahulu tidak langsung melalui proses hukum, oleh karena itu masyarakat Bali percaya akan datangnya hukum karma bagi sebuah tindakan yang dianggap sebagai sebuah kejahatan dengan menuliskannya pada t-shirt dijadikan sebagai sebuah harapan bahwa leluhur orang Bali itu tidak buta, melihat mana yang salah dan yang benar sehingga karma akan datang bagi mereka yang bertindak salah. Teks "Rutan polda Bali 27 Agustus 2020" merupakan penandaan tanggal dimana JRX mulai secara sah memasuki rutan polda Bali untuk mempertangungjawabkan perbuatannya di status sosial medianya.

\section{PENUTUP}

Simpulan

Dua buah desain t-shirt yang mengusung ideologi untuk pembebasan JRX SID lahir dari akun sosial media frontliner Bali dan akun sosial media danu_segara merupakan salah satu bentuk desain t-shirt yang lahir dari berbagai kelompok sosial masyarakat yang mengusung ideologi pembebasan JRX SID terhadap delik kasus yang menimpanya, desain t-shirt ini lahir dari aspirasi masyarakat yang menganggap negara telah menghegemoni kebebasan berpendapat di negeri ini telah mati dengan diseretnya JRX ke dalam jeruji penjara, desain - desain tersebut umumnya menggunakan ilustrasi JRX dengan penggayaan flat desain yang disimbolkan dengan tangan terikat dan mulut dibungkam, digambarkan juga bagaimana semangat menyuarakan aspirasi rakyat dengan kobaran api dan pengeras suara 
namun berakhir di dalam dinginnya jerusi besi, berbagai harapan atas JRX muncul mulai dari harapan atas kebebasan JRX hingga membawa juga sistem kepercayaan orang Bali yang dikenal dengan karma, dalam t-shirt tersebut kita dapat melihat banyak tanda dan makna tersembunyi yang terkait dengan konteks dipenjarakannya JRX yang dianggap sudah mengebiri demokrasi di negeri ini. Media T-shirt sangat baik digunakan sebagai medium aspirasi baik aspirasi pribadi maupun kelompok tertentu, karena medium t-shirt ini mampu menghadirkan ideologi - ideologi tertentu juga memasukkan unsur estetika di dalamnya sehingga mampu menarik pengguna t-shirt baik dari segi ideologi yang di usung maupun dari segi estetikanya.

\section{DAFTAR PUSTAKA}

Barnard, Malcom. 1996. Fashion Sebagai

Komunikasi. Yogyakarta : Jalasutra

Bocock, Robert. 2011. Hegemoni.

Yogyakarta : Jalasutra

Budiman, Kris. 2005. Ikonisitas. Yogayakarta

: Buku Baik.

Gramsci, Antonio. 2013. Prison Notebooks.

Yogyakarta : Pustaka Pelajar

Hikam, M.A.S., 1990, Perlawanan Sosial:

Telaah Teoritis dan Beberapa Studi

Kasus, Prisma, LP3ES, Jakarta.

Mangkunegara, Anwar Prabu. 2009. Perilaku

Konsumen. Bandung : Refika Aditama

Moleong, Lexy J (2010). Metodologi

Penelitian Kualitatif. Bandung : PT Remaja Rosdakarya

Piliang, Yasraf Amir. (2012). Semiotika dan

Hipersemiotika. Bandung : Matahari

Piliang, Yasraf Amir. (2018). Teori Budaya

Kontemporer. Yogyakarta : Cantrik

Pustaka

Siswati, Endah. 2017. Anatomi Teori
Hegemoni Antonio Gramsci. Jurnal

Translitera, Vol V,hIm 22-23

Wisudiatmika, Ida Bagus Adi. 2020. T-Shirt

Sebagai Media Perlawanan Terhadap

Wacana Reklamasi Teluk Benoa Bali.

Jurnal Studi Kultural, 2, vol 5, hlm 6-13

Satori, Djam'an dan Aan Komariah. 2012.

Metodelogi Penelitian Kualitatif.

Bandung : Alfabeta

Internet :

https://www.liputan6.com/regional/read/4

340525/berkas-dinyatakan-lengkap-

kasus-idi-kacung-who-segera-naik-

persidangan (jrx diborgol)

https://diyankcom.wordpress.com/2019/03

/22/legal-aspek-produk-teknologi-

informasi\%EF\%BB\%BF/ (foto profil jrx)

https://sejarahbali.wordpress.com/2015/06

/27/ubud-gianyar-bali/\#more-57 